\title{
Pendugaan Efisiensi Teknis dan Faktor-Faktor yang Mempengaruhi Produksi Broiler di Kabupaten Manokwari
}

\section{Estimation of Technical Efficiency and Factors Affecting Production Broiler in Manokwari Regency}

\author{
S. Pakage*, A. W. Wenda, A. P. E. Widodo, A. Baaka, dan D. A. Iyai \\ Fakultas Peternakan, Universitas Papua, 98314 - Indonesia \\ *Corresponding E-mail: stpakages@yahoo.com \\ (Diterima: 15 Juli 2020; Disetujui: 2 Oktober 2020)
}

\begin{abstract}
ABSTRAK
Usaha peternakan ayam pedaging/broiler adalah salah satu usaha yang sangat menjanjikan dan menguntungkan dan untuk meningkatkan keuntungan dibutuhkan penggunaan sumberdaya input secara efektif dan efisien. Tujuan penelitian ini adalah untuk mengetahui pengaruh faktor-faktor input terhadap produksi, mengetahui tingkat efisiensi teknis, dan untuk mengetahui keadaan skala produksi ayam pedaging di Kabupaten Manokwari. Penelitian ini dilakukan dengan metode survei kepada 30 responden yang dipilih secara sengaja. Variabel yang diamati yaitu jumlah produksi, bibit ayam/day old chick (DOC), pakan, obat vitamin dan vaksin, listrik, tenaga kerja, dan luas kandang. Data yang diperoleh kemudian diolah dan dianalisis dengan metode Ordinary Least Square (OLS) dan Maximum Likelihood Estimation (MLE). Hasil penelitian menunjukkan bahwa faktor DOC, pakan, obat vaksin dan vitamin, listrik, tenaga kerja, dan luas kandang secara bersama-sama mampu menjelaskan 96 persen $(\mathrm{R}-\mathrm{Sq}=96,00)$ dari variasi produksi dan berpengaruh terhadap produksi ayam pedaging yaitu nilai F-hitung $>$ F-tabel $\alpha=0,05, \mathrm{db}=5$, dbgalat $=24$ $(90,972>2,621)$. Secara terpisah bahwa faktor bibit (DOC) memilki pengaruh nyata dengan arah positif terhadap produksi. Faktor pakan dan luas kandang tidak berpengaruh namun memiliki arah yang sesuai dengan produksi, sedangkan faktor obat vaksin dan vitamin, listrik, dan tenaga kerja tidak berpengaruh dan arahnya negatif terhadap produksi ayam pedaging. Rata-rata peternak telah cukup efisien secara teknis dalam melakukan usaha $(\mathrm{TE}=0,9044)$ dan masih memiliki kesempatan untuk ditingkatkan sebesar 0,0956 persen. Disimpulkan bahwa faktor yang mempengaruhi produksi ayam pedaging adalah day old chick (DOC) dan peternak telah efisien secara teknis. Usaha peternakan ayam pedaging di Kabupaten Manokwari dalam keadaan decreasing return to scale.
\end{abstract}

Kata kunci: ayam pedaging/broiler, ordinary least square, maximum likelihood estimation, return to scale

\section{ABSTRACT}

The broiler business is one of the most promising and profitable companies and to increase profits requires the use of input resources effectively and efficiently. The purpose of this study was to determine the effect of input factors and the level of technical efficiency, and the state of the scale on broiler production in the Manokwari Regency. This research was conducted by a survey method on 30 respondents who were chosen deliberately. The observed variables were production, day-old chick (DOC), feed, vitamin and vaccine drugs, electricity, labor, and cage area. The data obtained were then processed and analyzed using Ordinary Least Square (OLS) and Maximum Likelihood Estimation (MLE). The results showed that the $D O C$, feed, vaccine and vitamin drugs, electricity, labor, and cage area together were able to explain 96 percent $(R-S q=96.00)$ of production variation and affected the production of broilers. Separately, DOC has a real influence with a positive direction on production. Factor feed and area of the cage did not affect production but have an order by production. While vaccine and vitamin drugs, electricity, and labor also did not influence, the direction was negative towards broiler production. The average breeder has been quite technically efficient in doing business $(T E=0.9044)$ and still has a chance to be increased by 0.0956 percent. It was concluded that the factors influencing the production of broilers were day-old chick (DOC), 
and breeders were technically efficient. The broiler business in Manokwari Regency is returning to scale in a decrease.

Keyword: broiler, ordinary least square, maximum likelihood estimation, returns to scale

\section{PENDAHULUAN}

Usaha peternakan ayam pedaging merupakan salah satu usaha yang memiliki peranan sangat penting bagi ketersediaan daging di Indonesia. Hal ini terbukti dari populasi ayam pedaging yang meningkat setiap tahun yakni pada tahun 2016 mencapai 1.632.568 ekor dan meningkat menjadi 1.698.369 ekor pada tahun 2017 (Dirjen Peternakan dan Kesehatan Hewan, 2017). Sedangkan bila ditinjau dari produksi daging, usaha peternakan ayam pedaging mampu menyumbang rata-rata 58,07\% dari total produksi (Dirjen Peternakan dan Kesehatan Hewan, 2017). Populasi dan produksi yang tinggi ini tidak terlepas dari beberapa aspek yang lebih unggul dibanding komoditi ternak lainnya, diantaranya sistem agribisnisnya yang lengkap dari hulu hingga hilir, masa produksi lebih singkat, dan konsumen selalu ada.

Kabupaten Manokwari merupakan salah satu daerah di Indonesia dan memiliki tingkat populasi serta produksi ayam pedaging tertinggi di Provinsi Papua Barat. Menurut data statistik BPS (2017), total populasi ayam pedaging di Provinsi Papua Barat yaitu 1.598.236 ekor, $46 \%$ berasal dari Kabupaten Manokwari sebagai penyumbang tertinggi, $35 \%$ dari Kabupaten Sorong dan sisanya berasal dari kabupaten lainnya. Berdasarkan produksi daging ayam pedaging, Kabupaten Manokwari juga menjadi penyumbang tertinggi yaitu $46 \%$ dari $1.300 .084 \mathrm{Kg}$ total produksi daging ayam pedaging di Provinsis Papua Barat, sedangkan Kabupaten Sorong $35,4 \%$ dan sisanya dari kabupaten lainnya. Populasi dan produksi yang tinggi tidak selalu menggambarkan keuntungan atau pendapatan yang maksimal bagi suatu usaha peternakan ayam pedaging, terlebih lagi bagi peternakan ayam skala kecil atau peternakan rakyat (Saragih, 2000). Kendala yang sering dihadapi peternakan rakyat diantaranya yaitu fluktuasi harga, baik harga dari faktor produksi (bibit ayam atau Day Old Chick, pakan, obatobatan dan vitamin, serta peralatan) atau pun dari harga jual produk yang dihasilkan yaitu ayam hidup dan daging ayam (Yemima, 2014). Hal ini dapat menjadi masalah serius bagi peternak, apabila biaya pengunaan faktor produksi lebih tinggi dibanding penerimaan yang diperoleh, maka dapat dipastikan peternak tidak memperoleh keuntungan.

Selain itu, beberapa kendala umum yang dialami peternak ayam pedaging di Manokwari yaitu harga bahan baku yang tinggi dan tidak stabil serta ketersediaannya yang terbatas dan tidak menentu. Selain itu, harga daging ayam pedaging hasil peternak lokal masih kalah bersaing dengan daging ayam beku dari daerah lain di Indonesia misalnya Surabaya yang memiliki harga jauh lebih rendah. Kedala seperti ini dapat mempengaruhi bahkan menurunkan pendapatan peternak. Menurut Ayakeding (2016) berdasarkan data sebaran, pendapatan usaha peternakan ayam pedaging sebagian besar pada kriteria yaitu sebanyak $60 \%$ rendah, $33 \%$ sedang dan $7 \%$ tinggi. Untuk meningkatkan pendapatan dan menekan tingginya biaya produksi salah satunya yaitu dengan mengurangi penggunaan beberapa faktor produksi yang berlebihan disebut efisiensi produksi. Pada umumnya peternak di Kabupaten Manokwari belum memperhatikan tingkat efisiensi faktor produksi usahanya dan hanya mementingkan pendapatan yang diterima. Oleh karena itu, pengetahuan tentang penggunaan faktorfaktor produksi secara efesien patut untuk diketahui oleh peternak ayam pedaging yang sedang menjalankan usaha dalam upaya meningkatkan pendapatannya.

Penelitian ini dilakukan dengan tujuan untuk: 1) Mengetahui pengaruh faktor-faktor 
produksi terhadap produksi ayam pedaging di Kabupaten Manokwari, 2) Mengetahui tingkat efisiensi teknis yang dicapai peternak ayam pedaging di Kabupaten Manokwari; dan 3) Mengetahui keadaan skala produksi usaha peternakan aya pedaging di Kabupaten Manokwari.

\section{METODE}

\section{Tempat dan Waktu Penelitian}

Penelitian ini dilaksanakan di Kabupaten Manokwari Provinsi Papua Barat. Pengambilan data dilakukan selama dua bulan yaitu pada awal Juli hingga akhir bulan Agustus 2019.

\section{Metode Subyek dan Sampel Penelitian}

Metode yang digunakan dalam penelitian ini adalah metode survei dengan teknik kuisioner. Subyek pada penelitian ini adalah beberapa peternak ayam pedaging yang ada di Kabupaten Manokwari. Dari total jumlah peternak ayam pedaging di Kabupaten Manokwari yaitu 65 peternak yang tersebar di beberapa distrik. Sampel ditentukan secara sengaja terhadap 30 peternak.

\section{Analisis Data}

Tahapan analisis data yang digunakan dalam penelitian ini yaitu:

1. Untuk mengetahui faktor-faktor yang mempengaruhi fungsi produksi usaha peternakan ayam pedaging dilakukan uji dengan metode Ordinary Least Square (OLS) dan Maximum Likelihood Estimation (MLE) pada model fungsi produksi Cobb-Douglas. Bentuk matematis atau model fungsi produksi usaha peternakan ayam pedaging adalah sebagai berikut:

$$
\begin{aligned}
\operatorname{LnY}= & \operatorname{Ln} \beta_{0}+\beta_{1} \operatorname{LnX}_{1}+\beta_{2} \operatorname{LnX}_{2}+\beta_{3} \operatorname{LnX}_{3} \\
& +\beta_{4} \operatorname{LnX}_{4}+\beta_{5} \operatorname{LnX}_{5}+\beta_{6} \operatorname{LnX}_{6}+(\text { Vi- } \\
& \text { Ui) }
\end{aligned}
$$

Keterangan:

$\mathrm{Y}=$ Produksi (ekor)

$\ln =$ Logaritma Natural e $=2,718$ $\beta_{0}=$ Kostanta

$\beta_{1}$ hingga $\beta_{6}=$ Parameter variabel input tidak tetap yang diduga

$\mathrm{X}_{1}=$ Bibit/DOC (ekor)

$\mathrm{X}_{2}=$ Pakan $(\mathrm{Kg})$

$\mathrm{X}_{3}=$ Obat, Vaksin, Vitamin (jumlah paket)

$\mathrm{X}_{4}=$ Tenaga kerja (Jumlah tenaga kerja)

$\mathrm{X}_{5}=$ Listrik (kwh)

$\mathrm{X}_{6}=$ Luas Kandang $\left(\mathrm{m}^{2}\right)$

$\mathrm{e}=$ Gangguan stokhastik atau kesalahan (Vi-Ui)

$\mathrm{Vi}=$ kesalahan yang dilakukan karena pengambilan secara acak

$\mathrm{Ui}=$ Efek dari efisiensi teknis yang muncul

2. Untuk menganalisis tingkat efisiensi teknis pada usaha peternakan ayam pedaging, dilakukan analisis efisiensi dengan opsi Technical Efficiency Effect Model. Untuk mengestimasi efisiensi teknis di tingkat peternak ayam pedaging, digunakan model fungsi produksi frontier stochastic. Model matematis fungsi tersebut adalah sebagai berikut:

$$
\mathrm{Yi}^{*}=\mathrm{f}(\mathrm{Xi} ; \beta)+\varepsilon \mathrm{i}
$$

$\mathrm{i}=1,2, \ldots . \mathrm{n}$

YYi* adalah output, $\mathrm{Xi}$ adalah variabel input aktual, $\beta$ adalah parameter dari diketahui, dan e adalah error term. Error term terdiri dari 2 komponen yaitu:

$$
\varepsilon \mathrm{i}=\mathrm{Vi}-\mathrm{Ui}
$$

Komponen Vi adalah error tem yang simetris dan diasumsikan identik, independent dan terdistribusi normal $\mathrm{N}\left(0, \sigma^{2} \mathrm{v}\right)$. Ui adalah error term yang bersifat independent terhadap $\mathrm{Vi}$ dan terdistribusi normal $\mathrm{N}\left(0, \sigma^{2} u\right)$. Error term ini memungkinkan fungsi produksi aktual berada dibawah fungsi produksi frontier.

Efisiensi teknis pada usahatani diartikan sebagai kondisi output aktual (Yi) terhadap output Frontier (Yi*) dengan menggunakan teknologi yang tersedia. Dengan demikian persamaan efisiensi teknis menjadi sebagai berikut: 


$$
\mathrm{TEi}=\frac{\mathrm{Yi}}{\mathrm{Yi} *}+\frac{E(Y i / u i, X i)}{E(Y i / u i=0, X i)}=E[\exp \cdot(-U i) / \varepsilon i]
$$

Nilai efisiensi teknis (TE) terletak dalam selang interval 0 sampai 1 atau $0 \leq$ TEi $\leq 1$. Nilai efisiensi teknis yang sama dengan 1 mengindikasikan bahwa usaha peternakan ayam pedaging dalam kondisi efisien dan apabila nilai efisiensi teknis yang lebih kecil dari 1 mengandung arti bahwa usaha peternakan ayam pedaging tersebut belum efisien serta apabila nilai efisiensi teknis yang diperoleh peternak adalah lebih besar dari 1 maka usaha peternakan ayam pedaging tersebut tidak efisien.

3. Untuk menganalisa Return to Scale (RTS) pada penelitian ini dilakukan dengan cara menjumlahkan nilai koefisien determinasi faktor-faktor produksi berdasarkan hasil dari Maximum Likelihood Estimation (MLE).

4. Untuk menerangkan hubungan sebab akibat dari faktor produksi dalam fungsi produksi dilakukan uji statistik.

Uji koefisien regresi simultan (Uji F)

Uji ini dilakukan untuk mengetahui apakah model penduga yang diajukan sudah layak untuk menduga parameter dan fungsi produksi. Uji yang digunakan adalah uji-F.

Prosedur pengujian:

H0: faktor produksi (Xi) tidak berpengaruh terhadap produksi ayam pedaging

H1: faktor produksi (Xi) berpengaruh terhadap produksi ayam pedaging.

Dimana:

$$
\text { F-hitung }=\frac{R^{2} /(n-1)}{\left(1-R^{2}\right) /(n-k)}
$$

$\mathrm{R}^{2}=$ koefisien deterninasi

$\mathrm{N}=$ jumlah data

$\mathrm{K}=$ jumlah parameter

Jika F-hitung $>$ F-tabel maka $\mathrm{H} 0$ ditolak, artinya faktor-faktor produksi secara bersamaan berpengaruh nyata terhadap produksi ayam pedaging. Tetapi jika F-hitung $<$ F-tabel maka H0 diterima, artinya faktor-faktor produksi secara bersama-sama tidak berpengaruh terhadap produksi ayam pedaging.

Uji koefisien regresi parsial (Uji-t)

Pengujian koefisien regresi dilakukan untuk mengetahui apakah faktor-faktor produksi (Xi) berpengaruh terhadap produksi ayam pedaging $(\mathrm{Y})$. Uji yang digunakan adalah uji-t.

Prosedur pengujian:

$\mathrm{H} 0$ = faktor produksi (Xi) tidak berpengaruh nyata terhadap produksi (Y)

$\mathrm{H} 1$ = faktor produksi $(\mathrm{Xi})$ berpengaruh nyata terhadap produksi (Y)

$$
\text { T-hitung }=\frac{b i}{S e(b i)}
$$

Dimana:

$\mathrm{bi}=$ Koefisien regresi

Se(bi) $=$ Standar deviasi dari bi

$i=1,2,3, \ldots, 7$

Jika T-hitung $>$ T-tabel maka $\mathrm{H} 0$ ditolak, artinya $\mathrm{Xi}$ berpengaruh nyata terhadap produksi (Y). Tetapi jika T-hitung $<$ T-tabel maka H1 diterima, artinya Xi tidak berpengaruh nyata terhadap produksi (Y).

Data dalam penelitian ini dianalisis dengan bantuan software Microsoft Exel 2010, Minitab17, dan Frontier versi 4.1c.

\section{HASIL DAN PEMBAHASAN}

\section{Analisis fungsi produksi dengan metode Ordinary Least Squares (OLS)}

Hasil dari analisis fungsi produksi dengan metode Ordinary Least Squares (OLS) tentang variabel-variabel input secara bersama-sama memberikan pengaruh terhadap jumlah produksi (Tabel 1). Hal ini dibuktikan dengan nilai koefisien determinasi yaitu sebesar $96,00 \%$ yang mengartikan bahwa variabel-variabel independen secara bersama-sama mampu menjelaskan 96,00\% dari variasi produksi ayam pedaging. Kemudian berdasarkan nilai F-hitung yaitu sebesar 90,972 dan apabila dibandingkan dengan nilai F-tabel pada $\alpha=0,05_{\mathrm{db}=5 \text {, dbgalat } 24}$ yaitu 2,621 .

Pendugaan Efisiensi Teknis dan ... (Pakage et al.) 
Tabel 1. Hasil Analisis dengan Ordinary Least Squares (OLS)

\begin{tabular}{lccc}
\hline \multirow{2}{*}{ Peubah } & \multicolumn{3}{c}{ OLS } \\
\cline { 2 - 4 } & Koefisien & std-error & T-ratio \\
\hline Konstanta & $-0,76258$ & 0,43251 & $-0,17631$ \\
Bibit (X1) & 0,74482 & 0,11435 & 0,65134 \\
Pakan (X2) & 0,16871 & 0,12034 & 0,14019 \\
OVV(X3) & $-0,29135$ & 0,26255 & $-0,11096$ \\
Listrik (X4) & 0,41425 & 0,37222 & 0,11129 \\
Tenaga Kerja (X5) & 0,52467 & 0,14800 & 0,35448 \\
Luas Kandang (X6) & 0,50132 & 0,60963 & 0,82234 \\
\hline R-Sq (adj) & & & 96,00 \\
\hline F-hitung & & & 90,972 \\
\hline
\end{tabular}

Sumber: Olahan data primer, 2019.

Analisis fungsi produksi dengan metode Maximum Likelihood Estimation (MLE)

Hasil analisis fungsi produksi stochastic frontier pada usaha peternakan ayam pedaging dengan metode Maximum Likelihood Estimation (MLE) tentang nilai T-ratio untuk menentukan suatu variabel berpengaruh atau tidak, nilai T-hitung atau T-ratio akan dibandingkan dengan nilai T-tabel pada $\alpha=0,025 \mathrm{db}$ galat $23(2,39787)$ (Tabel 2). Apabila hasil nilai T-hitung lebih besar dari nilai T-tabel (T-hitung $>$ T-tabel), maka variabel independen tersebut berpengaruh terhadap variabel dependen atau jumlah produksi. Sedangkan jika nilai T-hitung lebih rendah dari nilai T-tabel (T-hitung $<$ T-tabel), maka variabel independen tersebut tidak berpengaruh terhadap variabel dependen atau jumlah produksi ayam pedaging.

Untuk melihat seberapa besar dan arah pengaruh suatu variabel independen terhadap variabel dependen, dapat diketahui melalui nilai koefisien regresi atau nilai elastisitas produksi. Apabila nilainya sebesar $\mathrm{n}$ positif, maka setiap penambahan input sebesar $1 \%$ pada variabel independen tersebut akan menaikan sebesar $\mathrm{n} \%$ jumlah produksi ayam. Sedangkan apabila nilai nilainya sebesar $\mathrm{n}$ negatif, maka setiap penambahan input sebesar $1 \%$ pada variabel independen tersebut akan menurunkan sebesar $\mathrm{n} \%$ jumlah produksi ayam.

Masing-masing variabel independen memiliki hasil nilai T-ratio dan nilai koefisien regresi yang berbeda-beda (Tabel 2). Pembahasan hasil analisis fungsi produksi dengan metode Maximum Likelihood Estimation (MLE) dari masing-masing variabel independen dijabarkan sebagai berikut:

\section{Bibit DOC (X1)}

Koefisien regresi variabel bibit DOC mempunyai tanda positif dan besarnya adalah 0,84873 . Artinya setiap penigkatan bibit DOC $1 \%$ maka produksi ayam pedaging akan meningkat $0,84873 \%$. Nilai T-hitung lebih besar dari T-tabel dimana 8,07702 > 2,3978, sehingga variabel bibit (DOC) memiliki pengaruh terhadap produksi ayam pedaging. Hal ini diduga karena kualitas bibit DOC yang digunakan dalam usaha peternakan ayam pedaging sudah cukup baik sehingga mampu bertahan dan dipelihara hingga masa finisher.

Hasil ini sesuai dengan hasil penelitian yang diperoleh Sunarno (2017), bahwa bibit DOC memiliki pengaruh terhadap dengan produksi ayam broiler di Kabupaten Wonogiri, diduga karena bibit DOC yang dipelihara telah melaui proses pemilihan sehingga memiliki kualitas yang baik. Hasil penelitian Yunus (2009), juga memiliki hasil yang sama yaitu bibit DOC memberikan pengaruh yang 
JPI Vol. 22 (3): 321-331

Tabel 2. Hasil Analisis dengan Maximum Likelihood Estimation (MLE)

\begin{tabular}{lccc}
\hline \multirow{2}{*}{ Peubah } & \multicolumn{3}{c}{ MLE } \\
\cline { 2 - 4 } & Koefisien & std-error & T-ratio \\
\hline Konstanta & 0,13402 & 0,50113 & 0,26744 \\
Bibit DOC(X1) & 0,84873 & 0,10507 & 8,07702 \\
Pakan (X2) & 0,10967 & 0,74080 & 1,48045 \\
OVV(X3) & $-0,81553$ & 0,18389 & $-0,44347$ \\
Listrik (X4) & $-0,35991$ & 0,23835 & $-0,15099$ \\
Tenaga Kerja (X5) & $-0,32846$ & 0,31752 & $-0,10344$ \\
Luas Kandang (X6) & 0,28222 & 0,53630 & 0,52623 \\
\hline
\end{tabular}

Sumber: Olahan data primer, 2019.

dominan terhadap produksi ayam pedaging pola kemitraan dan mandiri. Menurut Praditia (2015), produksi ayam pedaging tidak hanya dipengaruhi oleh faktor pemeliharaan tetapi dipengaruhi juga oleh kualitas DOC. Kualitas DOC yang baik akan sangat mempengaruhi kelancaran proses produksi dan dapat menurunkan tingkat kematian ayam selama periode pemeliharaan (Siregar, 2008). Hasil penelitian yang dilakukan oleh Pakage et al. (2015); Ali et al. (2014); Alrwis and Francis (2003); Areerat et al. (2012); Ezeh et al. (2012) juga menemukan bahwa day old chick (DOC) berpengaruh terhadap produksi ayam pedaging.

2. Pakan (X2)

Koefisien regresi variabel pakan mempunyai tanda positif dan besarnya adalah 0,309 yang artinya bahwa setiap peningkatan $1 \%$ pakan maka akan meningkatkan produksi ayam pedaging sebesar $0,309 \%$. Sedangkan nilai T-hitung untuk variabel pakan adalah 1,48045 dan lebih kecil dari T-tabel atau $1,48045<2,39787$, sehingga variabel pakan tidak memiliki pengaruh terhadap jumlah produksi ayam pedaging. Hal ini diduga karena pakan yang dikonsumsi ayam tidak secara efisien digunakan untuk pembentukan daging tetapi lebih kepada aktivitas bergerak yang diakibatkan oleh kandang yang digunakan oleh peternak memiliki luasan yang besar atau tidak sesuai dengan kapasitas tampung (density) yang ideal. Rata-rata luas kandang ayam pedaging pada lokasi penelitian adalah sebesar $102,53 \mathrm{~m}^{2}$ dan ratarata DOC yang dipelihara sebesar 730 ekor. Data tersebut menunjukkan bahwa kapasitas tampung adalah $7 \mathrm{ekor} / \mathrm{m}^{2}$.

Selain luas kandang, diduga jenis kandang terbuka bisa saja menjadi penyebab terjadinya tingkat stress ayam bertambah karena suhu yang tinggi pada waktu siang hari dan perubahan suhu serta cuaca yang cepat berubah mengakibatkan stress ayam bertambah dan konsumsi ransum menjadi tidak efisien. Hal ini sesuai dengan pendapat Fijana (2012), bahwa konsumsi pakan dipengaruhi oleh suhu yang tinggi, suhu yang tinggi di negara tropis seperti di Indonesia dapat menimbulkan stress sehingga mempengaruhi perubahan fisiologis, hormonal dan tingkah laku ternak. Kemudian Rao (2002), juga menemukan bahwa suhu lingkungan yang tinggi merupakan stressor utama, suhu ideal pemeliharaan ayam berkisar $10-22{ }^{\circ} \mathrm{C}$ untuk mencapai bobot optimum dan $15-27^{\circ} \mathrm{C}$ untuk efisiensi ransum.

3. Obat, vitamin, dan vaksin (X3)

Variabel obat, vitamin, dan vaksin (OVV) memiliki koefisien regresi bernilai negatif sebesar $-0,81553$ yang berarti bahwa setiap penambahan 1\% OVV maka akan menurunkan produksi ayam pedaging sebesar $0,82 \%$. Nilai tersebut juga menunjukan bahwa penggunaan OVV telah berlebihan dengan yang harus diberikan. Sedangkan nilai T-hitung yang dihasilkan masih lebih rendah dari T-tabel atau $-0,81553<-2,39787$. Hal ini menunjukan bahwa secara statistik 
penggunaan OVV tidak berpengaruh terhadap produksi ayam pedaging.

Hasil ini sesuai dengan hasil yang diteliti oleh Yunus (2009), bahwa OVV memiliki pengaruh dan hubungan yang negatif terhadap jumlah produksi ayam pedaging. Sedangkan menurut Sunarno (2017), juga menemukan bahwa OVV tidak memiliki pengaruh dan arahnya negativ terhadap produksi ayam pedaging.

Penggunaan OVV tidak berpengaruh terhadap produksi diduga karena rata-rata peternak telah melakukan penggunaan OVV secara berlebihan. Penggunaan OVV seharusnya dengan kadar sewajarnya, apabila berlebihan atau tidak sesuai aturan pakai maka hasilnya akan mengurangi produksi. Meskipun jumlahnya sedikit, namun apabila penggunaan obat-obatan, vaksin dan vitamin tidak diberikan sesuai dosis yang dibutuhkan, karena meskipun jumlahnya sangat sedkit tetapi memiliki fungsi yang sangat penting bagi pertumbuhan dan kesehatan ayam pedaging (Sunarno, 2017).

\section{Listrik (X4)}

Nilai koifisien regresi dari variabel listrik (X4) bernilai negatif yaitu $-0,35991$ berarti setiap peningkatan $1 \%$ penggunaan listrik maka akan menurunkan jumlah produksi ayam pedaging sebesar $0,35911 \%$ (Tabel 2). Nilai T-hitung yang diperoleh lebih kecil dari T-tabel atau $-0,15099<-2,39787$ dengan demikian variabel listrik tidak memiliki pengaruh terhadap variabel produksi ayam pedaging. Hal ini diduga disebabkan karena penggunaan listrik untuk lampu yang digunakan sebagai pemanas pada masa brooding dan sebagai penerang pada masa grower hingga finisher. Penggunaan lampu yang berlebihan dapat meningkatkan suhu ruangan, dan dapat menyebabkan stress pada ayam yang dipelihara.

Hasil penelitian ini sesuai dengan temuan dari Yunus (2009), bahwa variabel listrik tidak berpengaruh nyata terhadap variabel produksi, namun menunjukan arah yang sesuai (positif) terhadap variabel produksi. Menurut Surya (2007), bahwa lampu penerangan tidak berpengaruh nyata terhadap konsumsi pakan ayam pedaging selama pemeliharaan, hal ini disebabkan karena temperatur yang tinggi akibat musim panas selama masa pemiliharaan ayam pedaging. Meskipun secara statistik tidak memiliki pengaruh, namun penggunaan listrik sangat dibutuhkan bagi peternak sebagai pemanas pada masa starter dan penerangan dimalam hari. Berdasarkan pengalaman peternak, penggunaan lampu diperuntukan agar ayam mendapatkan penerangan dimalam hari sehingga dapat membantu ayam pedaging untuk makan dan minum, serta dapat mengurangi resiko serangan predator.

\section{Tenaga Kerja (X5)}

Variabel tenaga kerja memiliki nilai koefisien regresi sebesar -0,32846 yang berarti setiap peningkatan tenaga kerja sebesar $1 \%$ maka akan menurunkan produksi ayam pedaging sebesar $0,33 \%$. Nilai T-hitung lebih rendah dari T-tabel yaitu $-0,10344<$ $-2,39787$ berarti bahwa variabel tenaga kerja tidak memiliki pengaruh terhadap variabel produksi, dan memiliki hubungan yang negatif terhadap variabel produksi ayam pedaging. Hal ini diduga disebabkan oleh jumlah tenaga kerja dan jam kerja masih relatif sama serta karena skala produksi yang dilakukan masih relatif sangat rendah.

Hasil penelitian ini sesuai dengan hasil yang diperoleh Pakage et al. (2015) bahwa tenaga kerja (labor) tidak memiliki pengaruh dan berhubungan negatif terhadap produksi ayam pedaging. Sedangkan berbeda dari hasil penelitian yang diperoleh Yunus (2009), bahwa tenaga kerja berpengaruh nyata terhadap kenaikan produksi tetapi pengaruhnya relatif kecil dan bernilai positif. Hal ini diduga disebabkan perbedaan pola peternakan dan rata-rata jumlah skala produksi serta jumlah tenaga kerja yang dipakai di masing-masing tempat penelitian berbeda.

\section{Luas Kandang (X6)}

Variabel luas kandang memiliki nilai koefisien regresi sebesar 0,28222 yang berarti 


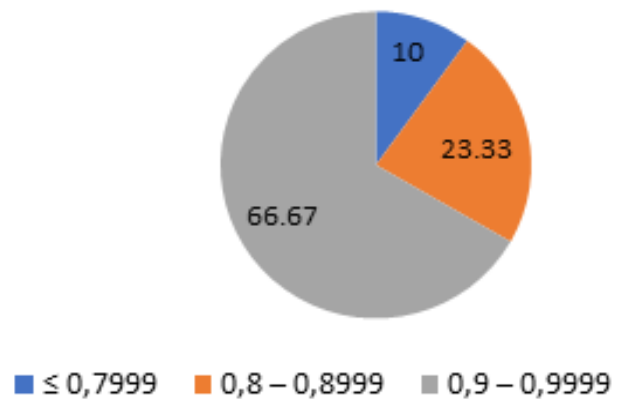

Gambar 1. Persentase Sebaran Efisiensi Teknis Usaha Ayam Pedaging

setiap peningkatan luas kandang sebesar $1 \%$ maka akan meningkatkan produksi ayam pedaging sebesar $0,28 \%$ (Tabel 2). Sedangkan nilai T-hitung yang dihasilkan yaitu sebesar 0,52623 dan lebih kecil dari T-tabel yaitu $0,52623<2,39787$ yang berarti variabel luas kandang tidak berpengaruh terhadap variabel produksi ayam pedaging. Hal ini diduga karena ukuran luas kandang lebih besar dan tidak sebanding dengan jumlah ayam yang dipelihara, rata-rata peternak tidak menggunakan sekat sebagai pembatas sementara dan proses pemanenan ayam tidak dilakukan serentak.

Hasil penelitian ini sesuai dengan hasil penelitian yang peroleh Yunus ( 2009), bahwa luas kandang tidak berpengaruh meskipun arahnya positif terhadap produksi ayam pedaging. Hal itu disebabkan waktu panen yang berbeda-beda antara peternak dan umur panen yang relatif singkat.

\section{Efisiensi Teknis}

Hasil penelitian menunjukan bahwa rata-rata tingkat efisiensi teknis yang dicapai adalah sebesar 0,9044. Hal ini mengindikasikan bahwa secara keseluruhan rata-rata produktivitas usaha peternakan ayam pedaging di Kabupaten Manokwari adalah sebesar $90,44 \%$ dari frontier. Nilai efisiensi teknis yang diperoleh tersebut lebih kecil dari satu. Nilai tersebut memberikan arti bahwa peternak ayam pedaging di Kabupaten Manokwari belum efisien secara teknis. Dengan demikian peternak ayam pedaging masih dapat melakukan upaya-upaya dalam penggunaan input yang lebih efisien sebesar
0,0956\%. Upaya-upaya ini dilakukan agar dapat mencapai tingkat efisiensi teknis yang maksimum dan mencapai peningkatan jumlah produksi.

Nilai efiseiensi teknis yang diperoleh terletak antara 0,52 sampai dengan 0,99 atau $52 \%$ sampai dengan $99 \%$ yang dikelompokkan kedalam tiga kategori (Gambar 1). Tingkat efisiensi sebagian besar usaha peternakan ayam pedaging di Kabupaten Manokwari sudah cukup efisien. Hal ini dibuktikan dari sebagian besar peternak $(66,67 \%)$ berada pada nilai indeks efisiensi maksimum sebesar 0,90,9999 , sisanya berada pada indeks efisiensi sedang $0,8-0,8999$ sebanyak $23,33 \%$ dan $\leq 0,7999$ sebanyak $10 \%$. Sebagian besar peternak ayam pedaging telah mencapai indeks efisiensi teknis yang maksimum atau hampir mendekati satu yaitu peternak-peternak tersebut telah mampu memaksimalkan penggunaan sumberdaya atau faktor-faktor produksi dalam usaha peternakan ayam pedaging. Sedangkan peternak yang lainnya berada pada kategori indeks efisiensi teknis sedang, yaitu peternak-peternak tersebut hanya mampu memaksimalkan separuh dari faktor-faktor input yang digunakan.

Perbedaan tingkat efisiensi diduga juga karena tata kelola penggunaan faktor-faktor input yang berbeda-beda antar peternak. Kemampuan dalam menentukan dan mengatur penggunaan faktor-faktor produksi atar peternak tentu berbeda-beda berdasarkan latar belakang pengalaman, pendidikan, serta usia, sehingga bisa saja menjadi penyebab tingkat efisiensi teknis usaha peternakan menjadi 
Tabel 3. Hasil Analisis Return to Scale (RTS)

\begin{tabular}{lc}
\hline Peubah & Koefisien \\
\hline Bibit DOC(X1) & 0,84873 \\
Pakan (X2) & 0,10967 \\
OVV (X3) & $-0,00816$ \\
Listrik (X4) & $-0,00360$ \\
Tenaga Kerja (X5) & $-0,03285$ \\
Luas Kandang (X6) & 0,02822 \\
\hline Total & 0,94203 \\
\hline
\end{tabular}

Sumber: Olahan data primer, 2019.

beragam. Hal ini sesuai dengan pendapat Yunus (2009), bahwa tingkat efisiensi peternak ayam pedaging pola kemitraan dan mandiri memiliki tingkat efisiensi teknis 0,87 yang sudah mendekati frontier (1) yang mencerminkan prestasi peternak ayam pedaging dalam keterampilan mengelola dan mengatur penggunaan faktor-faktor input agar lebih efisien. Penelitian Pakage et al. (2015) juga memberikan pendapat yang sama yaitu rata-rata efisiensi teknis peternak ayam pedaging pada sistem kandang tertutup dan sistem kandang terbuka memiliki keragaman antara $0,73-0,98$ dari rata-rata 0,93 , sehingga sudah mendekati frontier (1). Keragaman ini disebabkan karena perbedaan pengetahuan, penguasaan dan kemampuan pengambilan keputusan dalam mengelola usaha peternakan ayam pedaging.

\section{Return to Scale (RTS)}

Return to scale (RTS) merupakan gambaran kecenderungan atau trend skala produksi yang mampu dihasilkan apabila terjadi penambahan satu satuan input. Gambaran trend skala produksi yang tergambar terbagi dalam tiga jenis yaitu skala produksi yang meningkat, skala produksi yang tetap dan skala produksi yang menurun (Mubyarto, 1991). Nilai RTS dari produksi usaha peternakan ayam pedaging di Kabupaten Manokwari dapat diketahui melalui penjumlahan setiap koefisien variabel dependen.

Nilai total koefisien determinasi pada skala produksi yang tergambar dari hasil analisis efisiensi teknis pada usaha peternakan ayam pedaging di Kabupaten Manokwari yaitu decreasing return to scale atau skala produksi yang menurun (Tabel 3). Hal ini dibuktikan dari nilai total koefisien kurang dari satu $(0,94203<1)$ yang berarti bahwa setiap penambahan satu unit input menyebabkan penurunan pada skala produksi. Sehingga presentase peningkatan jumlah produksi ayam pedaging yang dihasilkan lebih rendah dibandingkan peningkatan penggunaan bibit DOC, pakan, obat-obatan, listrik, tenaga kerja, dan luas kandang.

Skala produksi yang menurun pada penelitian ini diduga disebabkan karena hanya terdapat satu variabel independen (bibit DOC) yang memiliki pengaruh sangat nyata dan sisanya (pakan, obat vaksin dan vitamin, listrik, tenaga kerja dan luas kandang) tidak memilki pengaruh, serta tiga dari variabel tersebut (obat vaksin dan vitamin, listrik, tenaga kerja) memiliki arah koefisien regresi yang negatif. Hal ini menunjukan bahwa penggunaan input atau variabel dependen seperti obat vaksin dan vitamin, listrik dan tenaga kerja telah berlebihan. Hasil ini berbeda dengan temuan Anandra (2010), bahwa usaha ternak ayam pedaging di Kabupaten Magelang dalam keadaan increasing return to scale dengan nilai RTS sebesar 1,009. Perbedaan hasil RTS diduga karena perbedaan tempat kedua penelitian, pengaruh faktor produksi dan latar belakang peternak yang berbeda. 


\section{KESIMPULAN}

Berdasarkan hasil analisis terhadap usaha peternakan ayam pedaging di Kabupaten Manokwari, maka dapat disimpulkan sebagai berikut:

1. Variabel input yang berpengaruh sangat nyata dan memiliki arah positif terhadap produksi adalah DOC, sedangkan pakan, dan luas kandang tidak berpengaruh tetapi memiliki arah yang positif. Variabel input seperti obat, vaksin, dan vitamin (OVV), listrik dan tenaga kerja memiliki arah yang negatif dan tidak berpengaruh terhadap produksi ayam pedaging.

2. Sebagian besar peternak ayam pedaging di Kabupaten Manokwari telah melakukan usaha ternak ayam secara efisien dari aspek teknis.

3. Usaha peternakan ayam pedaging di Kabupaten Manokwari dalam keadaan skala produksi dengan kecenderungan menurun (decreasing return to scale).

\section{DAFTAR PUSTAKA}

Ali, S. and B. Riaz. 2014. Estimation of Technical Efficiency of Open Shed Broiler Farmers in Punjab, Pakistan: A Stochastic Frontier Analysis. Journal of Economics and Sustainable Development. 5(7): 79-88.

Alrwis, K. N. and Francis, E. 2003. Technical efficiency of broiler farms in the central region of Saudi Arabia: stochastic frontier approach. Research Bulletin. 116(1): 5-34.

Anandra, A. R. 2010. Analisis Efesiensi Penggunaan Faktor-Faktor Produksi pada Usaha Ternak Ayam Pedaging di Kabupaten Magelang. Skripsi.

Areerat-Todsadee, H. K., Ngamsomsuk, K. and Yamauchi, K. E. 2012. Production efficiency of broiler farming in Thailand: A stochastic frontier approach. Journal of Agricultural Science. 4(12): 9752-
9760.

Arifien. 2002. Rahasia Sukses Memelihara Broiler di Daerah Tropis. Penebar Swadaya, Jakarta.

Ayakeding, G. S. 2016. Performans Usaha Peternakan Ayam Pedaging di Kabupaten Manokwari. Skripsi Sarjana Fakultas Peternakan Univesitas Papua. Manokwari.

BPS. 2014. Statistik Pemuda Indonesia 2014. Badan Pusat Statistik, Jakarta.

BPS. 2017. Provinsi Papua Barat dalam Angka. Manokwari: Badan Pusat Statistik Provinsi Papua Barat.

Dirjen Peternakan Dan Kesehatan Hewan. 2017. Statistik Peternakan dan Kesehatan Hewan 2017. Direktorat Jendral Peternakan dan Kesehatan Hewan Kementrian RI, Jakarta.

Ezeh, C. I., Anyiro, C. O. and Chukwu, J. A. 2012. Technical efficiency in poultry broiler production in Umuahia Capital Territory of Abia State, Nigeria. Greener Journal of Agricultural Sciences. 2(1): 001-007.

Fijana, E. S. 2012. Pengaruh Proporsi Pemberian Pakan pada Siang Malam Hari dan Pencahayaan pada Malam Hari Terhadap Produksi Karkas Ayam Broiler. Animal Agriculture Journal. 697-710.

Girinsonta. 1991. Beternak Ayam Pedaging. Kanisius, Yogyakarta.

Jondrow, J., Lovell, C. A. K., Materov, I. and Schimidt, P. 1982. On estimation of technical inefficiency in the stochastic frontier production model. Journal Econometrics. 19(1): 233-238.

Mardalis. 1990. Metode Penelitian (Suatu Pendekatan Proposal). Bumi Aksara, Jakarta.

Meiners, M. D. 2000. Teori Mikroekonomi Intermediate, Penerjemah Haris Munandar. PT. Raja Grapindo Persada, Jakarta.

Mubyarto. 1991. Pengantar Ekonomi

Pendugaan Efisiensi Teknis dan ... (Pakage et al.) 
Pertanian. LP3ES, Jakarta.

Murwanto, A. G. 2008. Karakteristik Peternak dan Tingkat Masukan Teknologi Peternakan Sapi Potong di Lembah Prafi Kabupaten Manokwari. Jurnal Ilmu Peternakan. 3(1): 8-15.

Noor, H. F. 2008. Ekonomi Manejerial. PT. Rajagrafindo Persada, Jakarta.

Pakage, S., Hartono, B., Fanani, Z. and Nugroho, B. 2015. Analysis of technical, allocative and economic efficiency of broiler production using closed house system in Malang District of East Java Indonesia. Livestock Research for Rural Development. 27(9).

Praditia, W. S. 2015. Efisiensi Produksi Peternakan Ayam Pedaging Riski Jaya Abadi Kebumen Ditinjau dari Efisiensi Manajemen, Teknis dan Ekonomis. Animal Agriculture Journal. 70-80.

Rao, D. N. 2002. Feeding to Minimize Heat Stress. Poultry Jurnal. 7-15.

Rasyaf, M. 1995. Manajemen Peternakan Ayam Broiler. Penebar Swadaya, Jakarta.

Riyadi. 2007. Analisis Faktor-Faktor yang Mempengaruhi Produksi Jagung di Kecamatan Wirosari Kabupaten Grobogan. Tesis Ilmu Ekonomi dan Studi Pembangunan. 0-115.

Saragih, B. 2000. Agribisnis Berbasis Peternakan (Kumpulan Pemikiran). USESE Foundation dan Pusat Studi Pembangunan IPB, Bogor.

Siregar, G. W. 2008. Optimalisasi Usaha Produksi Ayam Pedaging. Institut Pertanian Bogor, Bogor.

Soekartawi. 2003. Teori Ekonomi Produksi Dengan Pokok Bahasan Analisis CobbDouglas. PT. Raja Grafindo Persada, Jakarta.

Soroyah, I. A. 2016. Analisis FaktorFaktor Produksi yang Mempengaruhi
Nilai Produksi Industri Tenun Ikat di Kabupaten Jepara Jawa Tengah. Universitas Negeri Yogyakarta, Yogyakarta.

Sukiyono, K. 2004. Analisa Fungsi Produksi dan Efisiensi Teknis : Aplikasi Fungsi Produksi Frontier pada Usaha Tani Cabai Di Kecamatan Selupu Rejang. Rejang Lebong. Universitas Bengkulu.

Sulistyono. 1995. Menghindari Pemborosan Ransum. Majalah Poultry Indonesia, 20-23.

Sumartini. 2004. Kemitraan Agribisnis Serta Pengaruhnya Terhadap Pendapatan Usaha Ternak Ayam Pedaging di Kabupaten Bandung. Bandung: IPB.

Sunarno, E. S. 2017. Faktor-Faktor Yang Mempengaruhi Produksi Ayam Broiler di Kabupaten Wonogiri. UNIMUS, Semarang.

Suprijatna, K. D. 2005. Ilmu Dasar Ternak Unggas. Penebar Swadaya, Jakarta.

Suprijatna, K. D. 2006. Ilmu Dasar Ternak Unggas. Penebar Swadaya, Jakarta.

Surya, A. 2007. Pengaruh Warna Lampu Penerangan Terhadap Performa Ayam Broiler. Institut Pertanian Bogor, Bogor.

Sutawi. 1999. Agribisnis Peternakan. Universitas Muhammadiyah. Malang Press, Malang.

Yemima. 2014. Analisis Usaha Peternakan Ayam Broiler pada Peternakan Rakyat di Desa Karya Bakti, Kecamatan Rungan, Kabupaten Gunung Mas, Provinsi Kalimantan Tengah. Jurnal Ilmu Hewani Tropika. 3(1): 27-32.

Yunus, R. 2009. Analisis Efesiensi Produksi Usaha Peternakan Ayam Pedaging Pola Kemitraan dan Mandiri di Kota Palu Provinsi Sulawesi Tengah. Universitas Diponegoro, Semarang. 